\title{
Small Electric Vehicles in Commercial Transportation: Empirical Study on Acceptance, Adoption Criteria and Economic and Ecological Impact on a Company Level
}

\author{
Tim Hettesheimer, Cornelius Moll, Kerstin Jeßberger, \\ and Saskia Franz
}

\begin{abstract}
Small electric vehicles (SEVs) in commercial transportation have the potential to reduce traffic and its impacts, especially in urban areas. Companies, however, are still reluctant to implement SEVs. Therefore, the aim of this contribution is to shed light on the acceptance of motives for and obstacles to the use of SEVs in commercial transportation. Since the use of SEVs is often discussed in the context of innovative city logistics concepts, such as micro-hubs, our aim is also, to explore the acceptance, economic, and ecological potentials of SEVs in combination with micro-hubs. We use a multi-method approach and combine an online survey with in-depth interviews as well as a total cost of ownership (TCO) and $\mathrm{CO}_{2}$ calculation. Analyzing 350 responses to an online survey revealed that around half the companies surveyed have no knowledge of SEVs. This implies high unexploited potential, since $25 \%$ of these companies can imagine using them. In-depth interviews with logistics service providers (LSPs) or logistics departments from different sectors revealed that six of the 13 interviewed LSPs would be willing to implement this concept.
\end{abstract}

Keywords SEVs $\cdot$ Commercial transportation $\cdot$ TCO $\cdot$ CEP

\footnotetext{
T. Hettesheimer $(\triangle) \cdot$ C. Moll

Fraunhofer Institute for Systems and Innovation Research ISI,

Breslauer Straße 48, 76139 Karlsruhe, Germany

e-mail: tim.hettesheimer@isi.fraunhofer.de
}

K. Jeßberger

Julius-Maximilians-Universität Würzburg, Sanderring 2, 97070 Würzburg, Germany

S. Franz

Karlsruhe Institute of Technology (KIT), Kaiserstraße 12, 76131 Karlsruhe, Germany

(C) The Author(s) 2021

A. Ewert et al. (eds.), Small Electric Vehicles,

https://doi.org/10.1007/978-3-030-65843-4_6 


\section{Introduction}

Urbanization, economic growth, and structural economic changes have led to a steady increase in road transportation, especially in urban areas [1]. Approximately, $50 \%$ of urban traffic is caused by commercial vehicles [2]. This results in heavy congestion, air pollution, and greenhouse gas emissions in urban areas [3, 4]. When considering goods transport, it is striking that this only accounts for between 20 and $30 \%$ of total urban traffic, but is responsible for $80 \%$ of inner-city traffic jams during rush hours, for example, due to the double parking of delivery vehicles [5]. This situation could worsen in the future. Between 2000 and 2017, the number of courier, express, and parcel deliveries (CEP) in Germany doubled from 1.7 to 3.4 billion and, according to estimates, these are expected to increase further to 5 billion deliveries by 2025 [6]. In this context, the potential use of SEVs in commercial transportation and in the CEP industry in particular is a subject of increasing interest $[5,7]$. SEVs are much smaller compared to conventional delivery vans or trucks and require less space while in traffic or parking. Furthermore, they are lighter, more agile and, when being powered electrically, more energy efficient than conventional vehicles. Consequently, SEVs have the potential to reduce traffic and its impact, especially in urban areas.

While there are already a number of SEVs on city streets in private transport, they are still the exception for commercial transport services. The total user potential for commercial transport in Germany has already been estimated, for example, by Brost et al. [7], using data from the mobility survey "Mobility in Germany (MiD) 2017". However, this analysis based on so-called "regular professional trips" only allows an estimation of the maximum technically possible potential (such as driving range or load volume). Furthermore, it is important to note that company-specific criteria have a decisive influence on the user potential [7]. This contribution therefore focuses on a company-specific analysis of user potential. For this purpose, the results of a survey of more than 350 companies and 14 company-specific interviews are combined. This combination of the survey and the interviews allows for a cross-company view as well as a company-specific perspective on acceptance, potentials and obstacles for the use of SEVs in various commercial applications. This approach supports the aim of this contribution to assess the acceptance and company-specific reasons for or against the use of SEVs in commercial transport in general. In addition, due to the high relevance of CEP service providers for efficient urban traffic, an in-depth analysis was conducted on the acceptance and willingness of logistic service providers (LSPs) or logistics departments to use innovative concepts such as SEVs in combination with micro-hubs and on how this concept could contribute to the profitability and environmental impact of innovative city logistics concepts.

SEV definition. In this study, we showed the companies different SEV classifications in advance to give them an impression of the different characteristics of the individual classes. This was done using the following exemplary models: KEP10 
(L1e) as a two-wheeled cargo bike, three- and four-wheeled cargo bikes such as the Cargo Cruiser (L2e) or Loadster, the Paxter (L6e), and light electric vehicles such as Twizy Cargo and Microlino (L7e).

\section{Materials and Methods}

For the analyses of the general potential, an online survey was conducted of 4,000 companies on the distribution and applicability of SEVs in companies. The geographical focus is the "Technologieregion Karlsruhe". Companies of varying size from different sectors of industry were surveyed. The analysis covers the responses of more than 350 companies (return rate of $\sim 7.5 \%$ ).

In addition, interviews were conducted with 14 companies from industries that are considered the most suitable for SEVs in the literature. This involves installation service (1 company interviewed), painting trade (3), chimney sweeps (2), cleaning service (1), nursing service (1), CEP service (1), pharmacy (2), internal factory traffic (1), and delivery service (2). In some sectors, several companies were interviewed to find out whether and how the situation differs between companies in the same sector.

To answer the question about the acceptance of SEVs in combination with micro-hubs and how this concept could contribute to the profitability of innovative city logistics concepts, 13 semi-structured interviews were conducted with experts from different LSPs or logistics departments, supplemented by a total cost of ownership (TCO) calculation, an environmental analysis of $\mathrm{CO}_{2}$-emissions and a processing time analysis. In the interviews, besides evaluating the acceptance of LSPs to use innovative city logistics concepts, we derived logistics and economic data regarding the current transportations structures of the LSPs. The interview consisted of almost 50 questions. The data derived were used to calculate the TCO, processing times, and environmental impact $\left(\mathrm{CO}_{2}\right.$ emissions) of combining SEVs with micro-hubs.

When applying the TCO method, all relevant processes and procedures of a current and a future scenario or concept has to be analyzed and respective costs have to be specified. Since our interviews showed, that the CEP service industry is most likely to implement micro-hubs with cargo bicycles, we assumed that the original distribution structure is transformed to a micro-hub concept. In the status quo, a conventional delivery van starts the distribution of parcels to customers from a regional distribution center outside of an urban center. In the new concept, a battery-electric heavy-duty truck (HDT) transports two swap bodies (see Fig. 1), used as micro-hubs, from the regional distribution center to an urban center, while

\footnotetext{
${ }^{1}$ The region around the city of Karlsruhe, which is an industrial and technological center in the southern part of Germany, comprising approximately $3,240 \mathrm{~km}^{2}$ and 1.3 million inhabitants.
} 


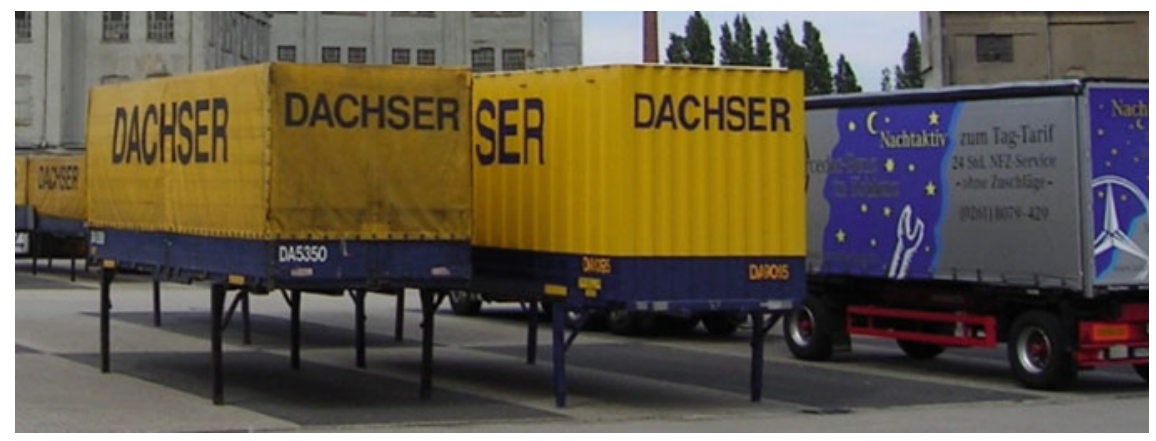

Fig. 1 Exemplary representation of swap bodies used as micro-hubs. Source Dachser Neuss Swap Bodies. Licensed under CC BY-SA3.0 (https://creativecommons.org/licenses/by-sa/3.0/ deed.de). Cut out. Original version: https://de.wikipedia.org/wiki/Datei:Dachser_Neuss_Swap_ Bodies.JPG

battery-electric three-wheeled cargo bicycles distribute the parcels from the swap bodies (micro-hubs) to the end-customers.

We considered the following costs, associated with the two logistics concepts: vehicle costs (fixed costs: annual depreciation, insurance costs and taxes; variable costs: fuel or electricity costs and costs for repair, maintenance, and tires), driver personnel costs, equipment and location costs for the micro-hubs and charging infrastructure costs for electrically powered vehicles. The calculations are based on the data collected in the semi-structured interviews. Missing data was collected through further literature and desk research. The logistics parameters used can be found in Table 1 and the techno-economic parameters in. Tables 2 and 3. Based on these data, we set up an average use case for each of the two logistics concepts and we retrieved average vehicle types, route lengths, break and working times, number of parcels to be delivered, etc. All costs, annually-fixed or variable, kilometer/usage-dependent costs, were broken down to a single parcel. For the calculation of the processing times, time for loading, unloading, delivering, transshipping and parking was considered. Regarding $\mathrm{CO}_{2}$-emissions, only emissions from energy consumption and thus, driving were considered, by employing respective emission factors.

\section{Results}

The following section presents the results of the online survey and key insights from the company interviews, followed by an in-depth analysis of combining SEVs with micro-hubs in the CEP industry. 
Table 1 Logistics parameters

\begin{tabular}{|c|c|c|c|c|c|}
\hline Parameter & Unit & Van & HDT & $\begin{array}{l}\text { Cargo } \\
\text { bicycle }\end{array}$ & Source \\
\hline Total number of stops/trip & $\#$ & 87.5 & 2 & 16 & \multirow{2}{*}{$\begin{array}{l}\text { Own calculation based } \\
\text { on interviews }\end{array}$} \\
\hline Total numbers of parcels/vehicle & $\#$ & 175 & 1,120 & 32 & \\
\hline $\begin{array}{l}\text { Number of parcels/swap bodies per } \\
\text { stop }\end{array}$ & $\#$ & 2 & 1 & 2 & Interview data \\
\hline Available vehicle volume & $\mathrm{m}^{3}$ & 12 & 69.1 & 2 & $\begin{array}{l}\text { Own calculation based } \\
\text { on interviews }[6,8- \\
11]\end{array}$ \\
\hline Capacity utilization & $\%$ & 90 & 90 & 100 & Interview data \\
\hline Used vehicle volume & $\mathrm{m}^{3}$ & 10.8 & 62.2 & 2 & $\begin{array}{l}\text { Own calculation based } \\
\text { on interviews }\end{array}$ \\
\hline Loading time per parcel/swap body & $\min$ & 0.5 & 16 & 0.5 & Own assumption \\
\hline Loading time per trip & $\min$ & 87.5 & 32 & 16 & $\begin{array}{l}\text { Own calculation based } \\
\text { on interviews }\end{array}$ \\
\hline $\begin{array}{l}\text { Unloading time per stop (with two } \\
\text { parcels/one swap body) }\end{array}$ & $\min$ & 3 & 10 & 2 & {$[12,13]$} \\
\hline Time loss per stop (parking) & $\min$ & 1 & 0 & 0 & Own assumption \\
\hline Un-/loading time per tour & $\min$ & 350 & 52 & 32 & $\begin{array}{l}\text { Own calculation based } \\
\text { on [14] }\end{array}$ \\
\hline Duration of stop between tours & $\min$ & & & 16 & $\begin{array}{l}\text { Own calculation based } \\
\text { on Interviews }\end{array}$ \\
\hline usable for charging & $\min$ & & & 16 & \multirow[t]{3}{*}{ Interview data } \\
\hline Duration of warehouse stop & $\mathrm{h}$ & 14 & 14 & 14 & \\
\hline usable for charging & $\mathrm{h}$ & 12 & 12 & 13 & \\
\hline Length of trip & $\mathrm{km}$ & 80 & 20.78 & 12 & $\begin{array}{l}\text { Own assumption } \\
\text { based on interviews }\end{array}$ \\
\hline in town & $\mathrm{km}$ & 66 & 6.78 & 12 & \multirow[t]{2}{*}{ Own assumption } \\
\hline out of town & $\mathrm{km}$ & 14 & 14 & & \\
\hline Number of trips per vehicle and day & $\#$ & 1 & 4 & 7 & Interview data \\
\hline $\begin{array}{l}\text { Distance between two stops (in } \\
\text { town) }\end{array}$ & $\mathrm{km}$ & 0.74 & & & \multirow[t]{4}{*}{ Own assumption } \\
\hline Distance to first stop & $\mathrm{km}$ & 8 & & & \\
\hline in town & $\mathrm{km}$ & 1 & & & \\
\hline out of town & $\mathrm{km}$ & 7 & & & \\
\hline Average speed in town & $\mathrm{km} / \mathrm{h}$ & 30 & 22 & & Expert knowledge \\
\hline Average speed daytime out of town & $\mathrm{km} / \mathrm{h}$ & 50 & & & $\begin{array}{l}\text { Expert knowledge, } \\
\text { own assumption }\end{array}$ \\
\hline
\end{tabular}


Table 2 Techno-economic parameters of vehicles

\begin{tabular}{|c|c|c|c|c|c|}
\hline Parameter & Unit & Van & HDT & $\begin{array}{l}\text { Cargo } \\
\text { bicycle }\end{array}$ & Source \\
\hline Number of trips & $\# / d$ & 1 & 4 & 7 & \multirow{2}{*}{$\begin{array}{l}\text { Own } \\
\text { calculations, } \\
{[15]}\end{array}$} \\
\hline Operating life & $\mathrm{y}$ & 8 & 10 & 6 & \\
\hline Vehicle price & EUR & 40,000 & 280,886 & 15,000 & $\begin{array}{l}\text { Following [16- } \\
18]\end{array}$ \\
\hline Fuel consumption & $\begin{array}{l}1 / 100 \mathrm{~km} \mathrm{kWh} / \\
100 \mathrm{~km}\end{array}$ & 11 & 158 & 1.6 & $\begin{array}{l}\text { Following [15, } \\
\text { 17] }\end{array}$ \\
\hline Fuel price & $\begin{array}{l}\text { EUR/l } \\
\text { EUR/kWh }\end{array}$ & 1.066 & 0.184 & & [19-21] \\
\hline $\begin{array}{l}\text { Maintenance, repair, } \\
\text { and tire costs }\end{array}$ & EUR/km & 0.11864 & 0.3976 & 900 p.a. & {$[15,17,22,23]$} \\
\hline Tax & EUR/y & 211 & 1,336 & & [17] \\
\hline Insurance costs & EUR/y & 4,400 & 7,105 & 900 & {$[17,23]$} \\
\hline List price charging point & EUR & & 10,000 & 2,000 & {$[24,25]$} \\
\hline $\begin{array}{l}\text { Operating life } \\
\text { infrastructure }\end{array}$ & $\mathrm{y}$ & & 15 & 15 & [26] \\
\hline List price batter & EUR & & & 719 & [27] \\
\hline Operating life battery & $\mathrm{Y}$ & & & 6 & [15] \\
\hline
\end{tabular}

Table 3 Further techno-economic parameters

\begin{tabular}{l|l|l|l}
\hline Parameter & Unit & Value & Source \\
\hline Driver wage daytime & $\mathrm{EUR} / \mathrm{h}$ & 25 & {$[28]$} \\
\hline Driver wage nighttime & $\mathrm{EUR} / \mathrm{h}$ & 28.8 & {$[16]$} \\
\hline Working days per year & $\mathrm{d} / \mathrm{y}$ & 300 & {$[14]$} \\
\hline Area of swap body & $\mathrm{m}^{2}$ & 18 & Own calculation \\
\hline Rent & $\mathrm{EUR} /\left(\right.$ month $\left.^{*} \mathrm{~m}^{2}\right)$ & 11.76 & Research on rental portal \\
\hline Annual rent & $\mathrm{EUR} / \mathrm{y}$ & 2,545 & Own calculation \\
\hline Emission factor WTW diesel & $\mathrm{kg} \mathrm{CO} / 1$ & 2.964 & {$[16]$}
\end{tabular}

\subsection{Results of the Online Survey: Diffusion of, Motives for and Barriers to the Use of SEVs}

In a first step, the results from the survey were analyzed to determine the extent to which SEVs are known or are already in use. Based on these findings, the company-specific reasons for or against the use of SEVs were then determined in a second step. 
The general knowledge about SEVs in the companies surveyed is evenly split between those who know about SEVs and those who do not. Accordingly, 50\% of the respondents have not yet heard of SEVs. $41 \%$ of respondents were familiar with two-wheeled cargo bikes. $26 \%$ were aware of light electric vehicles, slightly more than the $25 \%$ familiar with three- or four-wheeled cargo bikes (see left-hand part of Fig. 2). Once the current state of knowledge about SEVs had been identified, the next step was to ask whether the use of SEVs was generally conceivable from the viewpoint of the companies. For this purpose, all the companies were surveyed, i.e. those already familiar with SEVs and those not familiar with them. The results were that $3 \%$ of the companies said they already use SEVs and another $25 \%$ can imagine doing so. $71 \%$ cannot imagine using SEVs in their company at all (see pie chart in Fig. 2). This means that more than a quarter of all the surveyed companies can imagine using SEVs.

In this context, the question arises about the size of the companies that consider SEVs a potential solution. Are these mainly large companies or is the potential use independent of company size? Looking at the applicability of SEVs by company size as depicted in Fig. 3, it is noticeable that 2.5-5\% of all sized companies already use SEVs (although it should be noted here that the absolute figures are very low and range between one and six). In addition, parallel patterns emerge when looking at company size. With the exception of companies with more than 250 employees, $22-27 \%$ can imagine using SEVs, while 68-76\% cannot in each size group. For companies with more than 250 employees, the use of SEVs appears considerably more feasible. Here, $55 \%$ of the companies state that they can imagine using SEVs. Thus, although there were only a few large companies in the sample, they seem to offer high potential for the use of SEVs. All in all 102 companies can imagine using SEVs or are already using them. This willingness seems to exist across all company sizes, although it is particularly marked in large companies (see Fig. 3).

Moreover, this willingness seems also to exist across all sectors. It should be noted that the number of companies that replied is in some sectors quite small. However, with the exception of "Transport and storage" and "Financial and insurance services", companies from all sectors consider SEVs to be applicable in principle (see Fig. 4).

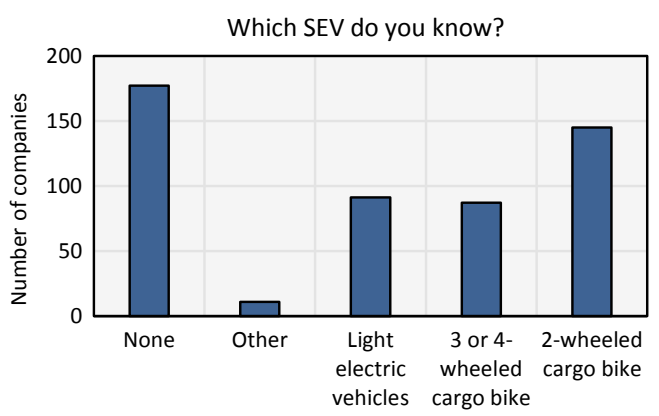

Can you imagine using SEV in your company?

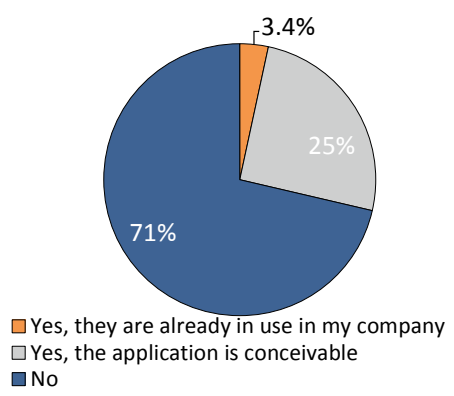

Fig. 2 Knowledge and applicability of SEVs in companies (own representation) 


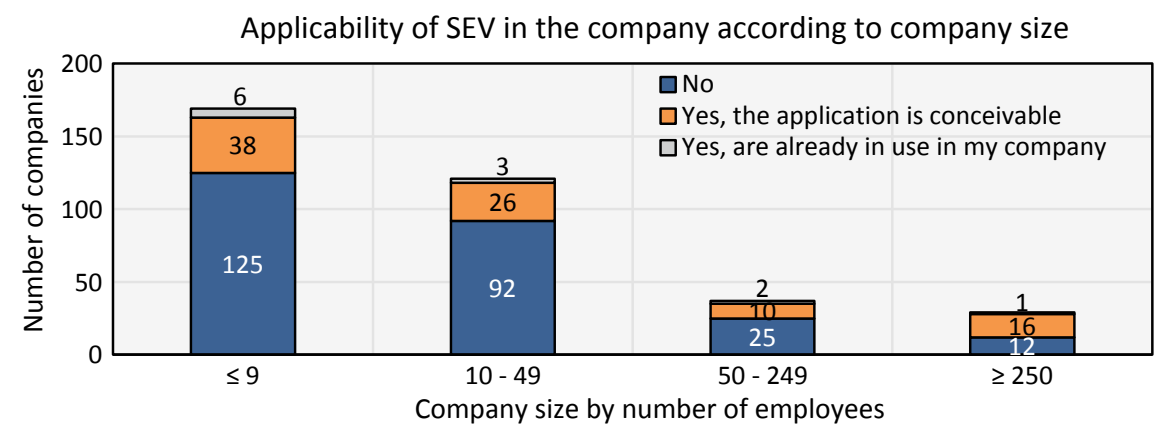

Fig. 3 Applicability of SEVs in companies according to size

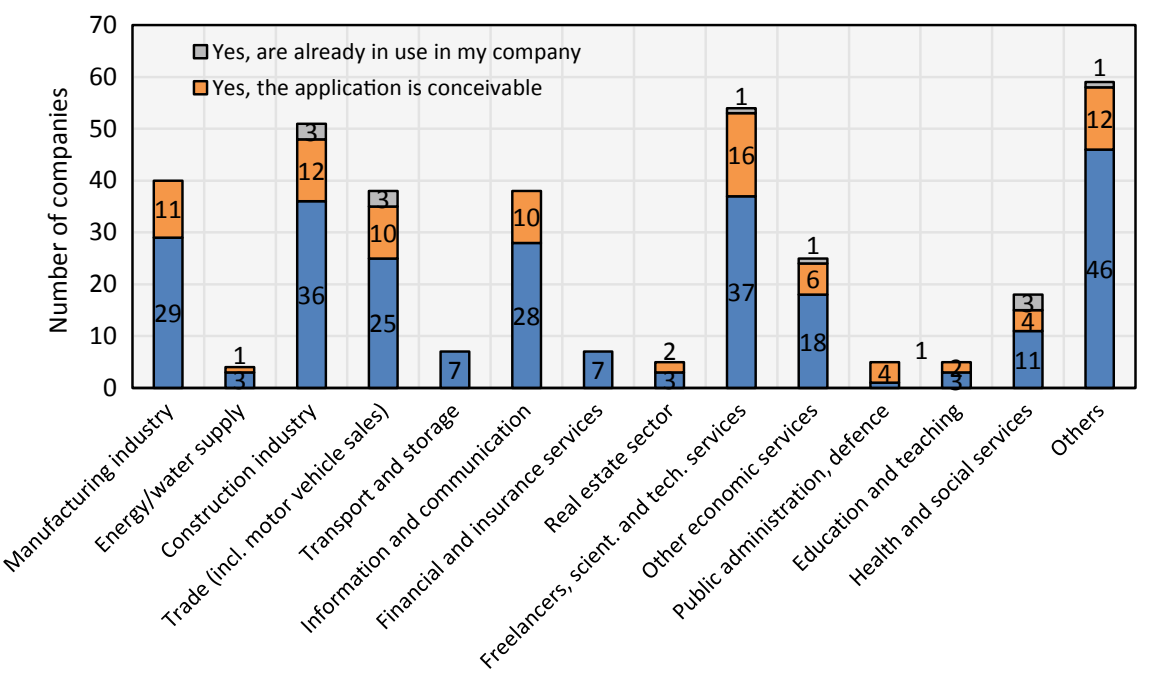

Fig. 4 Applicability of SEVs according to sectors

In this context, it is of interest to find out what advantages companies hope to gain from using SEVs and the 102 companies were questioned about their motives (see Fig. 5). Environmental protection seems to be the most important factor for using SEVs for micro, small and large companies. Reducing fuel costs is also cited as a strong motive. Furthermore, it is noteworthy that micro and small enterprises often have similar motives. In addition, being perceived as innovative is significantly more important for large companies than for other company sizes.

While the company-specific aspects that motivate a company to use SEVs are of interest, it is also essential to know which company-specific factors hinder the use of SEVs. An analysis was therefore conducted using the data from the companies that had previously stated that the use of SEVs was out of the question. Of the 254 respondents who could not imagine using SEVs in their company, 129 said the 
Which motives are decisive for you for the (possible) use of SEV?

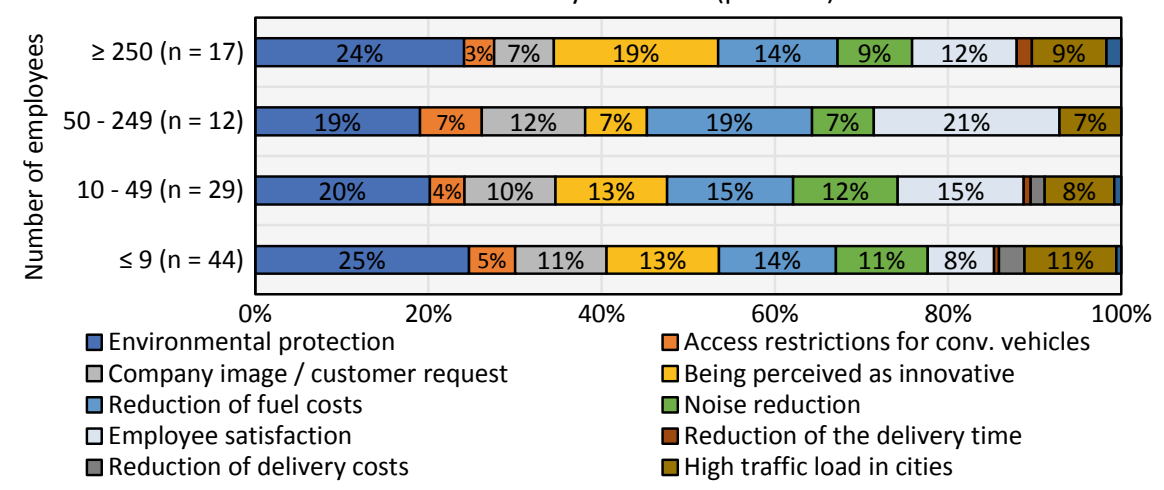

Fig. 5 Motives for the (possible) application of SEVs

reason is that they have no problems with their existing logistics that SEVs could solve. Seventy-seven mentioned that the range of SEVs was considered too limited, followed by insufficient transport volume and too small payload capacity with 64 and 63 mentions, respectively. Eighteen responses mentioned the lack of micro-depots as hindering the use of SEVs. It should be noted, however, that the lack of micro-depots may not be relevant in every economic sector. Examining the obstacles to use SEVs according to company size, it is noticeable that companies with up to 249 employees do not name logistics problems as the main reason. In the case of large companies, the aspect of insufficient range is mentioned most frequently. Figure 6 illustrates the results depending on the company size.

Which aspects do you see as hindering the decision to use a SEV?

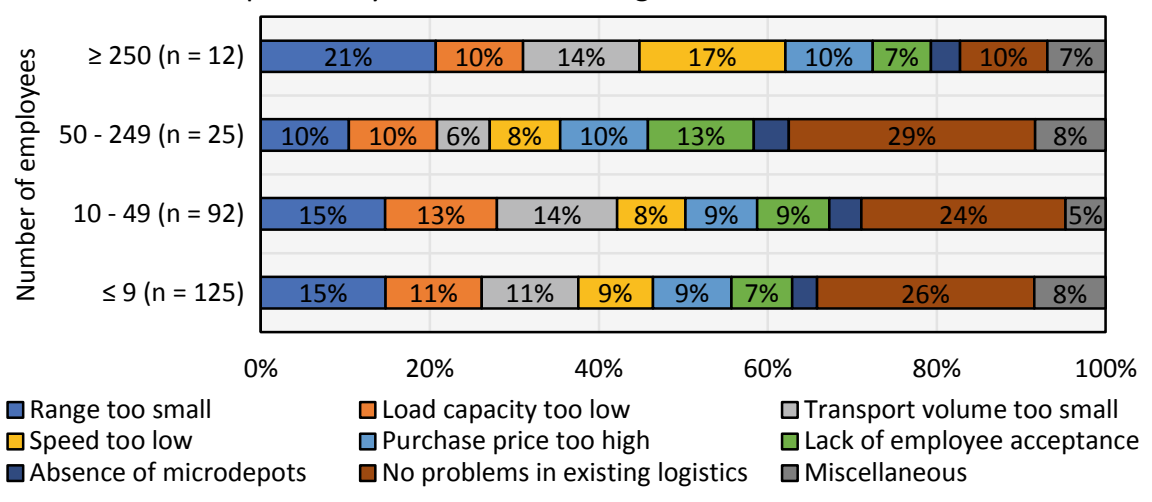

Fig. 6 Barriers to the use of SEVs 


\subsection{Supplementary Findings from Interviews with Companies from Potentially SEV-Relevant Sectors}

In order to gain a better understanding of the results of the online survey and why SEVs are considered or not considered by companies in a particular sector, supportive in-depth interviews were conducted with companies from sectors where SEVs might be a relevant option. A brief summary of the most important results of the interviews is presented below.

The statements of the interviewed companies showed that especially nursing services, CEP services, pharmacies, and internal factory traffic seem to be suitable for SEVs. The installation and chimney-sweeping sectors could integrate and use SEVs to some extent in their everyday work. Delivery services are, in principle, also suitable for SEVs in urban areas. Delivery speed is of enormous importance here, especially in the gastronomic sector, and SEVs are not always the fastest option.

It must be emphasized that it is difficult to make a general statement about the suitability of SEVs for an entire sector, as the requirements of companies in the same sector can already be very diverse and therefore a company-specific evaluation should always be made. For example, in the painting business, there are quite different requirements for the range and cargo weight of vehicles. Furthermore, interview partners from the chimney-sweep sector stated that the structure of their working districts varies widely. For example, one district has a diameter of $5.5 \mathrm{~km}$ and can be easily covered on foot. In contrast, other districts, which include single-family houses, for example, can be up to $17 \mathrm{~km}$ wide and would be suitable for SEVs.

An application of SEVs in the field of nursing services is quite conceivable. The advantages mentioned were more efficient and faster trips as well as reduced time needed to find a parking lot. Another major advantage is that employees without a category B driver's license could also use them if necessary. Using SEVs could therefore enlarge the pool of potential job applicants, as possession of a category B driving license would no longer be essential. This may also be an issue for other sectors.

In the installation sector, SEVs seem to be particularly suitable for customer services, while their loading volume is considered too small for cleaning services. They cannot transport ladders and larger machines, for example. In addition, other obstacles were also mentioned that are independent of the sector, such as the fact that company cars are sometimes also used privately and SEVs do not meet these requirements, and the lack of charging infrastructure at home. The potential lack of weather protection and lower performance in winter were also criticized. It should be mentioned that the results of the interviews are to be regarded as exemplary and not representative due to the different framework conditions of companies, even within the same sector. 


\subsection{Results from the In-Depth Interviews and Quantitative Analyses: Acceptance and Impact of SEVS for Micro-Hubs in the CEP Industry}

Using SEVs, such as three- or four-wheeled cargo bicycles, in commercial transportation is being increasingly discussed in combination with innovative city logistics concepts. In the logistics literature, one of the most promising solutions is to use SEVs for last-mile distribution from urban micro-hubs or depots [29, 30]. We therefore shed more light on the acceptance of combining electric cargo bicycles with urban micro-hubs and their economic and environmental impacts.

We interviewed CEP LSPs (5), logistics departments of wholesalers for groceries, paintings or other goods (3), transport companies (2), a distributor of a bakery chain (1), a distributor of a trading company (1) and a distributor of newspapers (1). The expert interviews revealed that six out of the thirteen interviewed LSPs would be willing to implement micro-hubs with cargo bicycles. Another LSP would probably implement that concept, while six LSPs would not implement it all (see Fig. 7).

The main reasons given for rejecting the concept of cargo bicycles with micro-hubs were very diverse. Most of the interviewees mentioned too low transportation capacities or the weight restrictions of cargo bicycles as the main reason. These LSPs tend to transport large and/or heavy goods, which are not suitable for cargo bicycles or SEVs in general. Another reason was missing cooling capabilities and difficulties with adhering to hygiene standards. Large quantities of goods that cannot be distributed efficiently with that concept and increased transportation lead-times due to transshipping at the micro-hubs were further reasons for rejecting this concept. Finally, the lack of profitability and a limited number of personnel or difficulties in recruiting new drivers were mentioned. In contrast, other companies responded that they had already implemented cargo bicycles with micro-hubs, at least in first pilot projects. Advantages were mentioned such as improved transportation cost efficiencies for the last mile and circumventing urban access regulations, especially in the morning, in the evening or during the night.

The logistics departments of wholesalers for painting or groceries were mostly reluctant to implement cargo-bicycles with micro-hubs, as were bakeries and pharmacies. Transport companies and general cargo carriers also rejected the

Willingness to implement cargo bicycles with micro-hubs

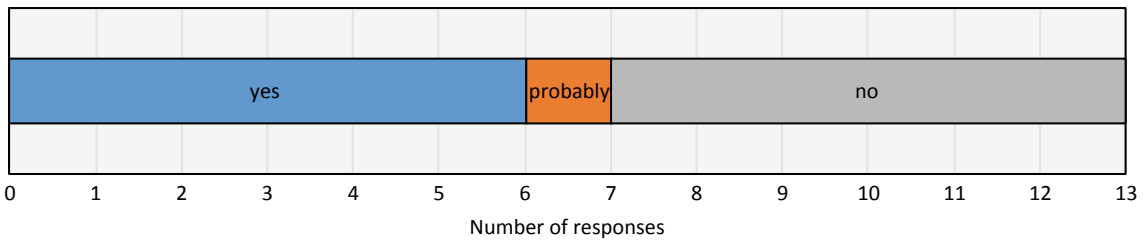

Fig. 7 Willingness of LSPs to implement cargo bicycles in combination with micro-hubs 
concept, mostly because their transported goods are too big and too heavy. Finally, one CEP LSP also rejected the implementation of micro-hubs. Distributors of newspapers, however, as well as other CEPs were willing to implement cargo bicycles with micro-hubs. One distributor of textiles could imagine using cargo bicycles with micro-hubs to distribute textiles ordered online to end-customers, while micro-hubs would not be an option for deliveries to retail stores.

In summary, acceptance of SEVs depends heavily on the logistics structures and general framework conditions, as well as on the type of transported goods. This is very industry-specific and the results show that the highest potential for cargo bicycles with micro-hubs is in the distribution of smaller goods, mainly to end-customers, which primarily concerns the CEP industry.

Based on these results, and considering the high acceptance of this concept among CEP LSPs, a quantitative analysis of the economic and environmental impacts was then carried out.

Figure 8 shows the results of calculating the TCO, $\mathrm{CO}_{2}$ emissions and processing time. Shifting from the status quo to cargo bicycles with micro-hubs would decrease transportation costs per parcel by $25 \%$. The main reason for this is that one cargo bicycle can actually replace one delivery van and cargo bicycles are much cheaper in terms of investments, as well as variable costs. We assumed that one van distributes 175 parcels on average on a standard tour lasting $9.7 \mathrm{~h}$. The loading capacity of a cargo bicycle was assumed to be 32 parcels and its distribution tours only take around $1.3 \mathrm{~h}$. In order to distribute the same number of parcels as a van, six bike tours are required, adding up to $9.4 \mathrm{~h}$ and including transshipping time at the micro-hub.

Cargo bicycles with micro-hubs can reduce the $\mathrm{CO}_{2}$ emissions per parcel by almost $80 \%$ (see Fig. 8). It has to be mentioned here that we only included the emissions from driving and excluded the emissions from the production of the

Economical and ecological impact and processing times
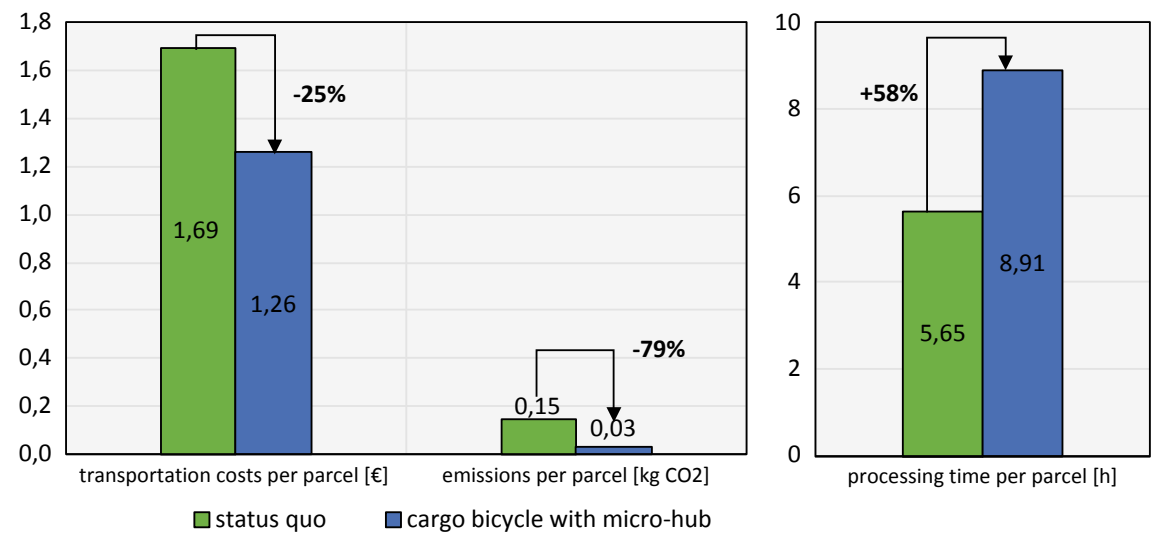

Fig. 8 Results of economical, ecological, and processing time calculations 
vehicles. Nevertheless, this represents a huge reduction. This is because electric drivetrains are much more energy-efficient than conventional internal combustion engines and electricity has a much lower $\mathrm{CO}_{2}$ emission factor than diesel. Reducing the emissions to zero would only be possible using $100 \%$ renewable electricity, which is currently not the case (calculations are based on Germany's power mix). Finally, average processing times would increase by almost $60 \%$. The processing time starts when a parcel leaves the regional distribution center and ends when it is delivered to the recipient. Thus, for the status quo, the parcel in the van is more or less directly on its way or at least on its final distribution tour to the recipient. For the micro-hub case, however, we assume that the micro-depots have to be distributed by the HDT (2 per HDT-tour), which takes extra time, as does transshipping at the micro-hub and only then can the cargo bicycle tour start from the micro-hub.

To sum up, from an economic and environmental perspective, electric cargo bicycles in combination with micro-hubs offer major benefits. Costs can be reduced by $25 \%$, while $\mathrm{CO}_{2}$ emissions can be reduced by $79 \%$. The only drawback is the higher processing time involved, which increases by $58 \%$.

\section{Summary and Conclusions}

SEVs can contribute to more sustainable commercial transportation due to their reduced size, lower noise emissions, and lower $\mathrm{CO}_{2}$ emissions. However, so far, only half of the companies surveyed know about them. Nevertheless, a quarter of these companies can imagine using SEVs, so there is a large user potential for SEVs in commercial transport. This potential is found in all sizes of companies, but especially in large ones. The main reasons for potentially using SEVs are not primarily monetary. Environmental protection and employee satisfaction are ranked first and second here. Thus, policy makers could use this intrinsic motivation to promote the diffusion of SEVs and thus reduce THG emissions. The reasons given for not using an SEV include no logistical advantage for the company and construction-related criteria such as transport weight, range or load volume. In order to activate the as yet unexploited potential, it is therefore advisable for SEV sellers to further inform companies about the existence and advantages of SEVs. In addition, the trial use of SEVs could offer the opportunity to show potential areas of application in companies that have not yet considered them.

The acceptance of electric cargo bikes in combination with innovative city logistics concepts, such as micro-hubs, is very high. Almost half of the interviewed LSPs would be willing to implement such a concept. However, acceptance depends to a large extent on the characteristics of the transported goods and thus, on the type and sector of the LSP. Bearing in mind, that electric cargo bikes would not be able to transport the bulk goods of many of the interviewees, the acceptance is high. The CEP industry, in particular, shows high acceptance of this concept, which offers economic and environmental benefits, but increased average processing 
times. The necessity of fast deliveries, however, is arguable. Consequently, for LSPs, electric cargo bicycles in a micro-hub concept represent an economically and environmentally beneficial solution with the potential to decrease urban traffic and make our cities greener.

Acknowledgements This contribution was written in the framework of the Profilregion Mobilitätssysteme Karlsruhe, which is funded by the State Ministry of Economic Affairs, Labour and Housing in Baden-Württemberg, and as a national High Performance Center by the Fraunhofer-Gesellschaft.

\section{References}

1. Fu, J., Jenelius, E.: Transport efficiency of off-peak urban goods deliveries: a Stockholm pilot study case studies on transport policy 6, 156-66 (2018)

2. Kampker, A., Deutskens, C., Maue, A., Hollah, A.: Elektromobile Logistik. In: Deckert, D. (ed.) CSR und Logistik. Spannungsfelder Green Logistics und City-Logistik, 1st edn, pp. 293-308. Springer Gabler (Management Series Corporate Social Responsibility), Berlin, Heidelberg (2016)

3. EEA: National emissions reported to the convention on long-range transboundary air pollution (LRTAP Convention). European Environment Agency, Copenhagen (2018)

4. Holguín-Veras, J., et al.: Direct impacts of off-hour deliveries on urban freight emissions. Transp. Res. Part D: Transp. Environ. 61, 84-103 (2018)

5. Prümm, D., Kauschke, P., Peiseler, H.: Aufbruch auf der letzten Meile. PricewaterhouseCoopers GmbH Wirtschaftsprüfungsgesellschaft, Neue Wege für die Städtische Logistik (2017)

6. Rumscheidt, S.: Die letzte Meile als Herausforderung für den Handel - ifo Schnelldienst 72 (1), 46-49 (2019)

7. Brost, M., Ewert, A., Schmid, S., Eisenmann, C., Gruber, J., Klauenberg, J.: Elektrische Klein-und Leichtfahrzeuge: Chancen und Potenziale für Baden-Württemberg. Studie im Auftrag der e-mobil BW (2019)

8. BIEK: Innovationen auf der letzten Meile: Kurier-, Express- Paketdienste (2017)

9. Graf, H.-W.: Optimierung des Wechselbrückentransports - ein Spezialfall der Tourenplanung Große Netze der Logistik: Die Ergebnisse des Sonderforschungsbereichs 559 ed P Buchholz and U Clausen (Berlin: Springer), pp. 101-28 (2009)

10. RYTLE GmbH: MOVR: Technische Daten, (2019). https://rytle.de/movr/. Last Accessed 2 Oct 2019

11. KRONE GmbH \& Co. KG: Dry Box: Typ: WK7,3 STG (2018)

12. Holguín-Veras, J., et al.: The New York City off-hour delivery program: a business and community-friendly sustainability program. Interfaces 48, 70-86 (2018)

13. Bogdanski, R.: Quantitative Untersuchung der konsolidierten Zustellung auf der letzten Meile (2019)

14. Arndt, W.-H.: Trends im urbanen Lieferverkehr Lieferkonzepte in Quartieren - die letzte Meile nachhaltig gestalten: Lösungen mit Lastenrädern, Cargo Cruisern und Mikro-Hubs ed W-H Arndt and T Klein (Berlin Difu), pp. 5-9 (2018)

15. Moll, C.: Nachhaltige Dienstleistungsinnovationen in der Logistik: Ein Ansatz zur Entwicklung von Entscheidungsmodellen. Springer Fachmedien Wiesbaden, Wiesbaden (2019)

16. Rosenberger, T., et al.: Der Lastauto Omnibus Katalog 2018. EuroTransportMedia Verlagsund Veranstaltungs-GmbH, Stuttgart (2017)

17. Mercedes-Benz, A.G.: Der neue Sprinter - Kastenwagen Tourer Fahrgestelle: Preisliste. Gültig ab 8. Februar 2018. Daimler AG (2018) 
18. Wietschel, M., et al.: Machbarkeitsstudie zur Ermittlung der Potentiale des Hybrid-Oberleitungs-Lkw. Fraunhofer ISI, Karlsruhe (2017)

19. IEA: World Energy Outlook 2018, International Energy Agency (2018)

20. Bundesverband der Energie und Wasserwirtschaft e. V., BDEW (2019) BDEWStrompreisanalyse Juli 2019: Haushalte und Industrie, Berlin

21. Gerbert, P., et al.: Klimapfade für Deutschland, BCG and Prognos AG (2018)

22. Onat, N.C., Kucukvar, M., Tatari, O.: Conventional, hybrid, plug-in hybrid or electric vehicles? State-based comparative carbon and energy footprint analysis in the United States. Appl. Energy 150, 36-49 (2015)

23. citkar GmbH: Loadster: Der Loadster All-Inclusive, (2019). https://loadster.org/produkt/ loadster-all-inclusive/. Last Accessed 6 Nov 2019

24. Hacker, F., Waldenfels, R., Mottschall, M.: Wirtschaftlichkeit von Elektromobilität in gewerblichen Anwendungen: Betrachtung von Gesamtnutzungskosten, ökonomischen Potenzialen und möglicher CO2-Minderung, Öko-Instiut e.V (2015)

25. NPE: Ladeinfrastruktur für Elektrofahrzeuge in Deutschland: Statusbericht und Handlungsempfehlungen 2015, Berlin (2015)

26. Urban-e GmbH \& Co.KG: Urban-e: Cargo eBikes for professionals!: KEP10, (2019). https:// www.urban-e.eu/. Last Accessed 2 Oct 2019

27. Schroeder, A., Traber, T.: The economics of fast charging infrastructure for electric vehicles. Energy Policy 43, 136-144 (2012)

28. Holguín-Veras, J., et al.: Fostering unassisted off-hour deliveries: the role of incentives. Transp. Res. Part A: Policy Pract. 102, 172-187 (2017)

29. Bienzeisler, B., Bauer, M., Mauch, L.: Screening City-Logistik. Europaweites Screening aktueller City-Logistik-Konzepte, Fraunhofer IAO (2018)

30. Dolati Neghabadi, P., Evrard Samuel, K., Espinouse, M.-L.: Systematic literature review on city logistics: overview, classification and analysis. Int. J. Prod. Res. 57(3), 865-887 (2019)

Open Access This chapter is licensed under the terms of the Creative Commons Attribution 4.0 International License (http://creativecommons.org/licenses/by/4.0/), which permits use, sharing, adaptation, distribution and reproduction in any medium or format, as long as you give appropriate credit to the original author(s) and the source, provide a link to the Creative Commons license and indicate if changes were made.

The images or other third party material in this chapter are included in the chapter's Creative Commons license, unless indicated otherwise in a credit line to the material. If material is not included in the chapter's Creative Commons license and your intended use is not permitted by statutory regulation or exceeds the permitted use, you will need to obtain permission directly from the copyright holder. 